\title{
HARDY AND RELLICH INEQUALITIES WITH REMAINDERS
}

\author{
W. DESMOND Evans AND Roger T. LEWIS
}

Abstract. In this paper our primary concern is with the establishment of weighted Hardy inequalities in $L^{p}(\Omega)$ and Rellich inequalities in $L^{2}(\Omega)$ depending upon the distance to the boundary of domains $\Omega \subset \mathbb{R}^{n}$ with a finite diameter $D(\Omega)$. Improved constants are presented in most cases.

Mathematics subject classification (2000): 47A63, 46E35, $26 \mathrm{D} 10$.

Key words and phrases: Rellich inequality, Hardy inequality, Remainder terms.

\section{REFERENCES}

[1] G. BARBATIS, Improved Rellich inequalities for the polyharmonic operator, Indiana University Mathematics Journal 55(4) (2006), 1401-1422.

[2] H. BREZIS AND M. MARCUS, Hardy's inequalities revisited, Dedicated to Ennio De Giorgi, Ann. Scuola Norm. Sup. Pisa Cl. Sci. (4) 25 (1997, 1998), 217-237.

[3] E.B. DAVIES, A Review of Hardy Inequalities. The Maz'ya Anniversary Collection, Vol. 2, Oper. Theory Adv. Appl., Vol. 110, pp. 55-67, Birkäuser, Basel,1999.

[4] E.B. DAVIES, Spectral Theory and Differential Operators, Cambridge Studies in Advanced Mathematics, Vol. 42, Cambridge Univ. Press, Cambridge, 1995.

[5] S. FilipPas, V. MAZ'ya, AND A. TertikAS, On a question of Brezis and Marcus, Calc. Var. Partial Differential Equations 25(4) (2006), 491-501.

[6] M. HofFMAnN-Ostenhof, T. HOFFMANN-OSTENHOF AND A. LAPTEV, A geometrical version of Hardy's inequality, J. Funct. Anal., 189 (2002), 539-548.

[7] E.H. LIEB AND M. Loss, Analysis, Graduate Studies in Mathematics, vol. 14, 2nd edition, American Mathematical Society, Providence, R.I., 2001.

[8] M. MARCUS, V.J. MizEL, AND Y. PINCHOVER, On the best constant for Hardy's inequality in $\mathbb{R}^{n}$, Trans. Amer. Math. Soc. 350 (1998), 3237-3255.

[9] T. MATSKEWICH AND P.E. SobOLEVSKII, The best possible constant in a generalized Hardy's inequality for convex domains in $\mathbb{R}^{n}$, Nonlinear Analysis TMA, 28 (1997), 1601-1610.

[10] M.P. OwEN, The Hardy-Rellich inequality for polyharmonic operators, Proc. Royal Society of Edinburgh, A 129 (1999), 825-839.

[11] J. TIDBLOM, A geometrical version of Hardy's inequality for $W_{0}^{1, p}(\Omega)$, Proc. A.M.S., 132(8) (2004), 2265-2271. 